\title{
pH-responsive magnesium- and carbonate-substituted apatite nano-crystals for efficient and cell-targeted delivery of transgenes
}

\author{
Ezharul Hoque Chowdhury
}

Faculty of Medicine, Nursing and Health Sciences, Jeffrey Cheah School of Medicine and Health Sciences, Monash University Sunway Campus, Jalan Lagoon Selatan, Bandar Sunway, Malaysia

Email: md.ezharul.hoque $@$ monash.edu

Received 27 February 2013; revised 29 March 2013; accepted 16 May 2013

Copyright (C) 2013 Ezharul Hoque Chowdhury. This is an open access article distributed under the Creative Commons Attribution License, which permits unrestricted use, distribution, and reproduction in any medium, provided the original work is properly cited.

\section{ABSTRACT}

The short half-lives due to the enzymatic degradation in blood, the lack of tissue targetability and the incapability to passively diffuse across the plasma membrane and smoothly traffic across the harsh intracelluar environment are the major shortcomings for nucleic acid-based potential therapeutics, such as recombinant plasmid and antisense oligonucleotides or small interferring RNA (siRNA). Plasmid DNA containing a gene of interest could have immense impact as a promising therapeutic drug for treating genetic as well as acquired human diseases at the molecular level with high level of efficacy and precision. Thus both viral and non-viral synthetic vectors have been developed in the past decades to address the aforementioned challenges of naked DNA. While in the viral particles plasmid DNA is integrated into the viral genome, in most non-viral cases the DNA being anionic in nature is electrostatically associated with a cationic lipid or polymer forming lipoplex or polyplex, respectively, or a cationized inorganic gold, silica or iron oxide particle. Due to the potential immunogenicity and carcinogenicity issues with the viral particles, non-viral vectors have drawn much more attention for the clinical evaluation. However, the main concern of using non-biodegradable particles, specially the inorganic ones, is the adverse effects owing to their long term interactions with body components. We have recently developed biodegradable pH-sensitive inorganic nanoparticles of $\mathrm{Mg} / \mathrm{CaPi}$ and carbonate apatite for efficient transgene delivery to primary, cancer and embryonic stem cells, by virtue of their high affinity binding with the DNA, ability to contact the cell membrane by ionic or ligand-receptor interactions and fast dissolution kinectis in endosomal aci- dic $\mathrm{pH}$ facilitating release of the DNA from the dissolving particles and also from the endosomes.

Keywords: Gene Therapy; Nanoparticles; Particle Dissolution; $\mathrm{Ca} / \mathrm{Mgpi}$; Carbonate Apatite; Endosome, Nucleus; Gene Expression

\section{INTRODUCTION}

Extensive research in the past decades on genomics and proteomics has led to the comprehensive understanding of the functional roles of proteins in the signal transduction pathways for phenotype regulation. Since both genetic and acquired human diseases are generally associated with up- or down-regulation of various genes and consequential over-expression or suppression of gene products, such as mRNA and proteins, treatment strategies could virtually target any of the three cellular macromolecules (genes, mRNAs and proteins) either by inhibiting or restoring their functions within the cells. However, treatment of a disease at the genetic level by either supplying a functional gene into the nucleus in order to be transcribed into a functional mRNA (i.e., replacement of a defective gene with a wild-type one) or blocking the translation of a mRNA to a particular protein by a specific siRNA or antisense oligonucleotide, is much superior over conventional drug therapy in terms of precision and efficacy, eliminating the off-target effects [1-5]. In addition, immunization against a pathogen by one or more gene(s) responsible for the pathogenecity is also seemingly more advantageous and effective than the classical immunization using a damaged pathogen with respect to safety and potency. Thus, considering the potentially revolutionary applications of "gene therapy" and "genetic vaccination", design of a smart vehicle is an indispensable task for intracellular delivery of DNA- or 
RNA-based genetic materials.

Viral systems are by far the most effective means of DNA delivery to mammalian cells, but some major limitations including toxicity, immunogenicity, restricted targeting of specific cell types, limited DNA carrying capacity, production and packaging problems, recombination and high cost, hamper their successful applications in basic research and clinical medicine. The effectiveness of a viral particle is the result of its highly evolved and specialized structure basically composed of a protein coat surrounding a nucleic acid core. Such a highly organized structure can prevent viral particles from unwanted interactions with serum components, while promoting subsequent internalization by the cells, escaping from the endosomes, and releasing genetic material from the particle either before or after entering the nucleus [6-10]. Development of a nonviral approach having the beneficial virus-like properties and lacking the disadvantageous ones would emerge as the most attractive one for implementation in research laboratories and gene therapy.

Here, we report on the current progress and development of $\mathrm{pH}$-sensitive inorganic nanoparticles of $\mathrm{Mg}^{2+}$ substituted calcium phosphate $(\mathrm{CaPi})$ and carbonate apatite for efficient and targeted delivery of transgenes into primary, cancerous and embryonic stem cells.

\section{MECHANISM OF DNA DELIVERY BY CLASSICAL CaPi PARTICLES}

$\mathrm{CaPi}$ precipitation has been one of the most widely used methods due to its simplicity, cost effectiveness and efficacy, for delivery of plasmid DNA to mammalian cells expressing a desirable transgene (known as "transfection") since the technique was developed in 1973 [11]. Despite being one of the oldest transfection methods, the procedure has remained almost unchanged, basically composed of either direct or drop-wise mixing of two solutions, one containing DNA and calcium chloride $\left(\mathrm{CaCl}_{2}\right)$ and the other possessing inorganic phosphate (Pi) (either $\mathrm{NaH}_{2} \mathrm{PO}_{4}$ or $\mathrm{Na}_{2} \mathrm{HPO}_{4}$ ) in order to induce "supersaturation" of the final solution with respect to $\mathrm{CaCl}_{2}$ and $\mathrm{Pi}$, resulting in precipitation of microscopically visible and invisible particles with the DNA being adsorbed through electrostatic interactions [12-14]. Although the particles have net negative charge, they are capable of binding anionic DNA presumably through the $\mathrm{Ca}^{2+}$-rich domains instead of the $\mathrm{PO}_{4}^{3-}$-rich sites existing on their surfaces. X-ray diffraction and FT-IR analysis of the precipitated particles established them as "hydroxyapatite" with the molecular formula of $\mathrm{Ca}_{10}\left(\mathrm{PO}_{4}\right)_{6}(\mathrm{OH})_{2}$ [12-14]. The resulting DNA/CaPi co-precipitates are usually dispersed onto the cultured cells from several hours to overnight in the incubator allowing them to be taken up by the cells via endocytosis. The internalized DNA is thus entrapped into the acidic compartments of endosomes which can subsequently be fused with the lysosomes of relatively lower $\mathrm{pH}$, where the DNA is usually fragmented by hydrolytic enzymes (nucleases). However, treatment with glycerol $[12,15]$ or chloroquine $[15,16]$ can help release functional DNA from the acidic vesicles to the cytosol in return for some extent of cell toxicity. Depending on whether the cell is dividing, like a cancer cell or nondividing like most of the normal cells in our body, cytosolic plasmid DNA can enter the nucleus at the time when the nuclear membrane is disrupted during mitosis or slowly pass through the nuclear pores by passive diffusion, respectively [5]. As a result, like other non-viral vectors, transcription of the nuclear translocated DNA and subsequent translation of the resulting mRNA to a particular protein are substantially high in cancer cells compared to nonmitotic or slowly dividing cells.

\section{APPROACHES FOR REGULATION OF PARTICLE GROWTH: INFLUENCES ON CELLULAR UPTAKE OF DNA}

CaPi precipitation in a supersaturated buffered solution of $\mathrm{Ca}^{2+}$ and $\mathrm{Pi}$ is controlled by the concentration of the individual reactant, incubation time and temperature and the ionization state of $\mathrm{Pi}$ which in turn depends on $\mathrm{pH}$ of the solution. In general, $\mathrm{DNA} / \mathrm{CaPi}$ co-precipitates are generated by mixing a solution containing $250 \mathrm{mM} \mathrm{Ca}{ }^{2+}$ (2X) and desirable amount of plasmid DNA with a $2 \mathrm{X}$ HEPES-buffered saline (HBS) of $\mathrm{pH} 7.05$, containing 1.5 $\mathrm{mM} \mathrm{Pi}$, followed by incubation at room temperature. With a decrease or an increase in the value of any of the parameters, such as concentration of $\mathrm{Ca}^{2+}$ or $\mathrm{Pi}, \mathrm{pH}$ of the HBS, incubation time or temperature, supersaturation development of the resulting solution will be reduced or enhanced, respectively, generating either too few or too high number of the particles. In addition, by changing more than one parameter at a time, such as, an increase in $\mathrm{Ca}^{2+}$ concentration and a decrease $\mathrm{Pi}$ level, it is possible to develop the same degree of supersaturation as required to produce effective co-precipitates [17]. Similarly, by increasing the $\mathrm{pH}$ of the HBS from 7.05 to 7.5 and incubation temperature from $25^{\circ} \mathrm{C}$ to $37^{\circ} \mathrm{C}$ and decreasing the $\mathrm{Ca}^{2+}$ concentration from $125 \mathrm{mM}$ to $14 \mathrm{mM}$, a similar level of supersaturation development was feasible, enabling to effectively co-precipitate DNA and carrying out transfection in serum-free condition [18]. Since the co-precipitation reaction and subsequent cell transfection were performed at the same temperature $\left(37^{\circ} \mathrm{C}\right)$, there was no further induction of particle formation or growth even in the absence of serum, whereas the existence of serum is essential during the transfection period for coating the particle surface and thus blocking further production and growth of the particles in the former case which involves lower temperature $\left(25^{\circ} \mathrm{C}\right)$ for the particle precipitation and higher temperature $\left(37^{\circ} \mathrm{C}\right)$ for the trans- 
fection [10]. However, the transfection in $10 \%$ serumsupplemented medium was significantly higher than in serum-free medium probably due to the particles of larger size formed in the latter case, since endocytosis is usually more effective for the particles of smaller size [18].

\section{DEVELOPMENT OF Ca-Mg PHOSPHATE (Ca/MgPi) NANOPARTICLES FOR EFFICIENT DELIVERY OF DNA}

In spite of the great efforts made in the past for controlling the growth kinetics of $\mathrm{CaP}$ precipitation by optimizing the parameters of reactant concentrations, $\mathrm{pH}$, incubation period and temperature, the first modification of the particles at the molecular level in order to delicately regulate the particle size was achieved by partially substituting $\mathrm{Ca}^{2+}$ with another divalent cation, $\mathrm{Mg}^{2+}$. The resulting particles of $\mathrm{Ca} / \mathrm{MgPi}$ precipitates, like $\mathrm{CaPi}$ ones, adsorb DNA, but unlike the latter, could prevent the growth of the precipitates to a significant extent, leading to huge uptake of DNA and consequential efficient transgene expression, which is 10 to 100 times higher than the classical $\mathrm{CaPi}$ co-precipitation method in HeLa and NIH3T3 cells [13].

Mixing of a $300 \mu \mathrm{l}$ of aqueous solution containing increasing doses of $\mathrm{Mg}^{2+}$ along with $250 \mathrm{mM}$ of $\mathrm{Ca}^{2+}$, with a 300 ul of 2 XHBS (pH 7.05) having $1.5 \mathrm{mM}$ of Pi resulted in a dramatic decline in particle diameter from 2.5 um up to $500 \mathrm{~nm}$ for $30 \mathrm{~min}$ incubation at room temperature, depending on the concentrations of initially added $\mathrm{Mg}^{2+}$. Clearly, with an increase in the amount of $\mathrm{Mg}^{2+}$ substituting $\mathrm{Ca}^{2+}$ in the apatite structure, the particle size decreased transforming the particle diameter from 500 $\mathrm{nm}$ to below $100 \mathrm{nM}$ at $80 \mathrm{mM}$ of $\mathrm{Mg}^{2+}$ for $1 \mathrm{~min}$ incubation. The estimated molar ratios of $\mathrm{Ca}, \mathrm{Mg}$ and $\mathrm{P}$ present in the precipitates of $\mathrm{Ca} / \mathrm{MgPi}$ indicated formation hydroxyapatite with the molecular formula of $\mathrm{Ca}_{10-\mathrm{X}} \mathrm{Mg}_{\mathrm{X}}\left(\mathrm{PO}_{4}\right)_{6}(\mathrm{OH})_{2}$ for 0.58 and 1.03 percentage of $\mathrm{Mg}$ and octacalcium phosphate (OCP) with the formula of $\mathrm{Ca}_{4-\mathrm{X}} \mathrm{Mg}_{\mathrm{X}}\left(\mathrm{PO}_{4}\right)_{3}$ for 1.76 to 3.16 percentage of $\mathrm{Mg}$ substituted in the particles [13]. The uptake of fluorescence-labeled plasmid in HeLa cells indicated size-dependent endocytosis of the $\mathrm{Ca} / \mathrm{MgPi}$ particles with the particles of the smaller size resulting in higher uptake of the DNA compared to those of bigger size, implying in agreement with the notion that internalization of apatite particles is indeed size-dependent $[18,19]$.

\section{ESTABLISHMENT OF CARBONATE APATITE NANOPARTICLES AS SMART DNA CARRIERS}

Bicarbonate-buffered medium is widely used for cell culture. Addition of relatively low amount of $\mathrm{Ca}^{2+}(3-5 \mathrm{mM})$ to such medium ( $\mathrm{pH}$ 7.5) containing endogenous $\mathrm{Pi}$, followed by incubation at $37^{\circ} \mathrm{C}$, resulted in microscopically visible particles which were apparently absent in the incubated HBS containing the same doses of total $\mathrm{Ca}^{2+}$ and $\mathrm{Pi}$, implicating that bicarbonate is one of the reactants in generation of those particles. Elemental analysis and FTIR of the lyophilized powder of the sedimented particles suggested the structure of typical carbonate apatite, a major component of hard tissues in our body [20,21]. Xray diffraction patterns demonstrated the widening of the peaks as indicative of poor crystallinity unlike those for highly crystalline hydroxyapatite as formed with $\mathrm{CaPi}$ precipitation [20,21]. Thus, the chemical reaction for particle formation takes place among $\mathrm{Ca}^{2+}, \mathrm{PO}_{4}^{3-}$ and $\mathrm{HCO}_{3}^{-}$, and DNA can electrostatically be associated with the cationic $\left(\mathrm{Ca}^{2+}\right.$-rich)domains of the particles [20, 21]. The two crucial factors for determining transfectionpotency, namely, the number and the average size of the particles are dramatically influenced by the concentrations of calcium, phosphate and bicarbonate, the $\mathrm{pH}$ of the medium and the incubation period and temperature (Figure 1). Increasing the concentration of any of the reactants (calcium, phosphate and bicarbonate) accelerates particle growth by providing a stronger driving force for the reaction while the other parameters $(\mathrm{pH}$, incubation time and temperature) are constant. On the other hand, an increase in $\mathrm{pH}$ and temperature (or incubation period) mainly shifts the ionization equilibrium of phosphate towards the forward direction, thereby favoring the particle generation by increasing the reaction rate, accompanied by growth and aggregation of the particles $[20,21]$. However, like $\mathrm{Mg}^{2+}$ in $\mathrm{Ca} / \mathrm{MgPi}$, bicarbonate as a minor component of the final apatite product with the molecular formula of $\mathrm{Ca}_{10}\left(\mathrm{PO}_{4}\right)_{6-\mathrm{X}}\left(\mathrm{CO}_{3}\right)_{\mathrm{X}}(\mathrm{OH})_{2}$, prevents the aggregation and generates smaller crystals in a dosedependent manner (Figure 2). Finally, due to the small size of the crystal having an average diameter of $50-300$ $\mathrm{nM}$, and strong binding affinity towards the DNA, carbonate apatite can effectively be transferred into the cell with the embedded DNA through endocytosis, following electrostatic interactions with the plasma membrane. The efficiency of cellular uptake of DNA was estimated to beat least 10-times higher than that for classical CaPi method [20,21].

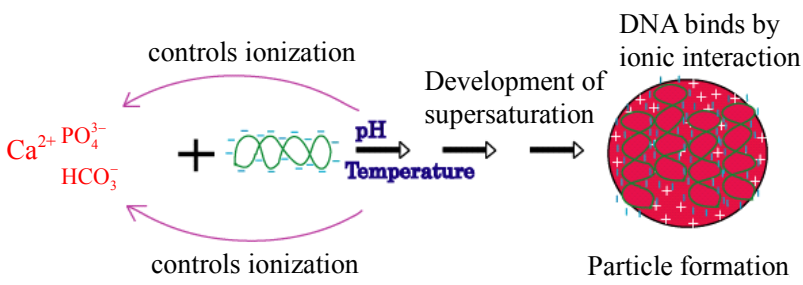

Figure 1. A proposed molecular mechanism for generation of $\mathrm{pH}$-sensitive carbonate apatite nano-crystals. 
Novel strategy for controlling apatite crystal size in nanometer scale

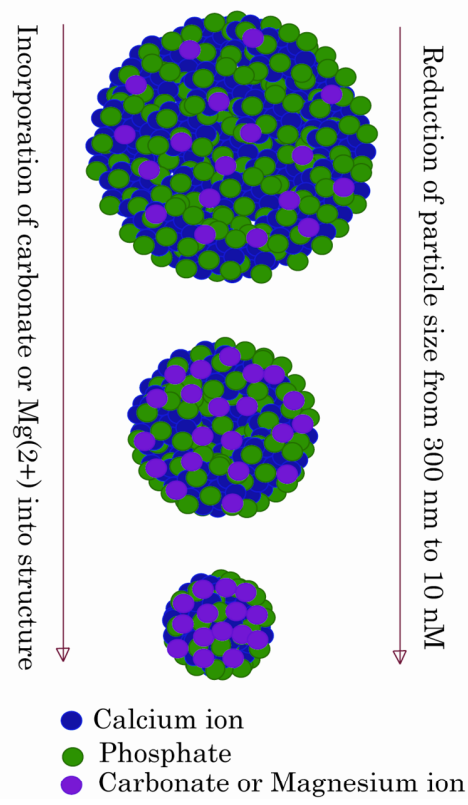

Figure 2. A schematic presentation of controlling particle size in accordance with the initially adjusted doses of $\mathrm{Mg}^{2+}$ and $\mathrm{HCO}_{3}^{-}$.

Transport of nanoparticle-associated plasmid DNA across the cell membrane is the first step of cellular traffic of the DNA which is usually subjected to massive degradation by lysosomal nucleases accounting for much lower transgene expression than the viral counterpart in terms of the total number of plasmid copies initially given. Among the other major barriers are inability of escaping the endosomes and difficulty in nuclear translocation. Depending on the type of carriers, DNA can be released from the particles in the acidic compartments, cytosol or nucleus mostly by interacting with the cellular macromolecules. Endosomal escape of the DNA either in free form or in complexation with the particles is guided by distinct mechanisms. For expression of the DNA carried by carbonate apatite, acidic environment of the endosomes (or lysosomes) was found essential, since inhibition of v-ATPase, a proton pump involved in the acidification process, resulted in almost complete inhibition of the expression. Moreover, modifying carbonate apatite to the higher state of crystallinity (i.e., with lower acid solubility) by incorporating fluoride or strontium ions into the apatite structure, transgene expression could surprisingly be prevented despite the uptake of the DNA by $100 \%$ of the treated cells. We therefore propose that once the particles are inside the endosomes, exposure to an increasingly acidic environment results in the consumption of the excess $\mathrm{H}^{+}$by phosphate and carbonate ions of the particle, leading to the particle dissolution, the swelling and rupture of the endosomes following passive chloride influx as a consequence of the potential difference across the endosomal membrane, and the resulting release of the DNA in cytosol (Figure 3). Therefore, inorganic crystals with higher acid solubility or lower crystallinity would enable quicker DNA release in endosomes than the

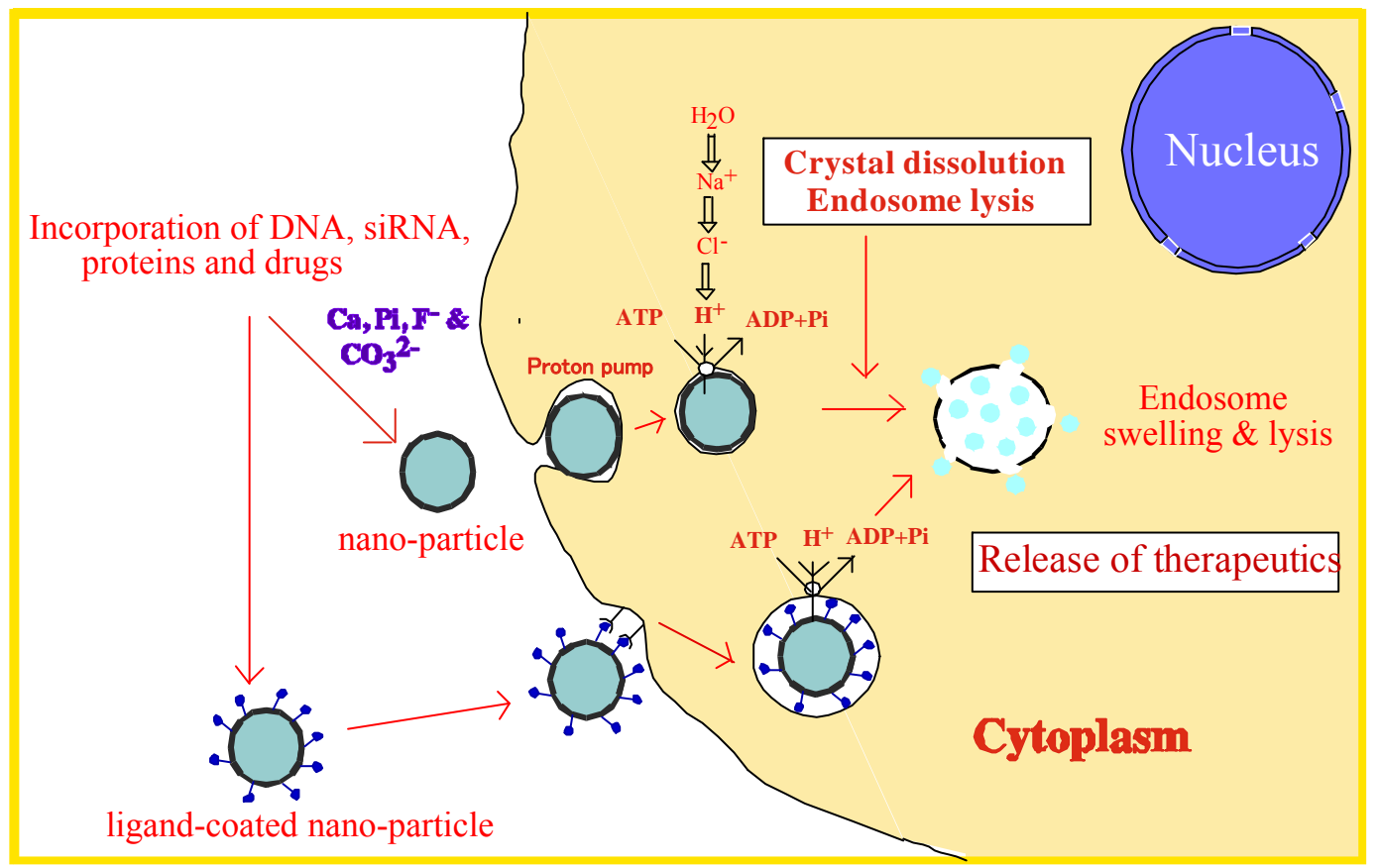

Figure 3. An summarized overview of intracellular delivery and expression of the plasmid DNA carried by carbonate apatite nano-crystals. 
crystals with lower solubility or higher crystallinity. Finally, the released DNA can enter the nucleus either through the nuclear pore or during cell division (Figure 3), promoting high level of transgene expression both in primary and cancer cell lines with an efficiency 5- to 100-times higher than with the conventional CaPi co-precipitation method or lipofectamine in serum-supplemented media [20,21].

\section{TARGETING pH-SENSITIVE INORGANIC NANOPARTICLES FOR RECEPTOR-SPECIFIC TRANSGENE DELIVERY}

The major goals for delivering a transgene(s) to a selected cell type are to increase the expression efficacy in those particular cells and prevent the side effects owing to its expression in other cells. A common strategy in non-viral cases involves the attachment of a targeting moiety to a polycationic backbone of lipid or polymer which subsequently condenses the DNA through ionic interactions. Polylysine, the first cationic plomer used for gene delivery, was conjugated to a diverse set of cell-targeting ligands, such as asialoorosomucoid, transferrin, EGF, mannose, fibroblast growth factor (FGF) and antibodies for receptor-specific delivery into hepatocytes via asialoglyco protein receptors, transferrin receptor-positive cells, EGF receptor-carrying cells, macrophages through membrane lectins, FGF receptor-bearing cells and lymphocytes via surface-bound antigens, respectively [4].

The fascinating surface properties of carbonate apatite due to the existence of two unique $\mathrm{Ca}^{2+}$ - and $\mathrm{PO}_{4}^{3-}$ / $\mathrm{CO}_{3}^{2-}$-rich domains, can facilitate binding of either anionic or cationic macromolecules to the particles by electrostatic interactions. In an innovative approach, the particle surface area was successfully coated sequentially with a cell-recognizable protein, such as asislofetuin for targeting asialoglycoprotein receptors present on hepatocytes or transferrin for transferrin receptors on several cancer cell lines and a highly hydrophilic protein, such as serum albumin for blocking non-specific interactions of the particles with other cell membrane-anchored or free serum proteins as well as preventing aggregation with other neighboring particles [10]. The functionalized particles with dual surface properties were shown to accelerate both transgene delivery and expression solely in the particular receptor-bearing cells.

In addition, by mimicking the natural mineralization process, extracellular matrix (ECM) proteins, such as collagen or fibronectin having strong affinity for the apatite particles, were successfully immobilized onto the nanocrystals for integrin-specific delivery and expression of a transgene [22]. Similarly, fibronectin-coated nanoparticles of $\mathrm{Ca} / \mathrm{MgPi}$ were successfully utilized for transgene expression in the corresponding integrin expressing cell line [23].

A notable success was achieved in transfecting embryonic stem cells which were resistant to the interactions with the particles alone resulting in low uptake and expression of a reporter gene. However, when the particles were complexed with a naturally occurring fibronection and a genetically engineered E-cadherin-Fc in presence of DNA, a synergistic effect on the uptake of the DNA led to a dramatic enhancement in transgene expression in mouse embryonic stem cells which possess both transmembrane fibronectin-specific integrin and E-cadherin [24-26]. A further enhancement in transgene expression with the same bio-functional nanoparticles was observed by activating protein kinase $\mathrm{C}$ (PKC) in the same cells, since PKC in "inside-out" signaling cascade can enhance integrin affinity toward ECM proteins, promoting cell adhesion and spreading and also, up-regulate endocytosis and recycling of E-cadherin [27].

In a human $\mathrm{T}$ leukemia cell line (Jurkat), nano-crystals of carbonate apatite in association with the surface-embedded fibronectin and/or E-cadherin-Fc, could also enhance transgene delivery and the expression efficacy was dramatically accelerated up to 150 times by selectively disrupting the actinfilaments [28].

\section{CONCLUSION}

Development of $\mathrm{pH}$-sensitive nanoparticles of $\mathrm{Ca} / \mathrm{MgPi}$ and carbonate apatite has basically led to the creation of a new branch of therapeutic delivery tools based on biocompatible and bio-mimicking inorganic materials with huge potential for extensive pre-clinical and clinical applications. In spite of the current availability of a good number of organic or inorganic non-viral vectors and their derivatives, an ideal system in terms of the efficacy, tissue targetability and safety is still missing for clinical implementations. The dual surface charges and $\mathrm{pH}$ responsiveness of $\mathrm{Mg}^{2+}$ - and $\mathrm{CO}_{3}^{2-}$-substituted apatite are two amazing features conferring the binging affinity for potential therapeutics, flexibility in surface modification for cell targetability and dissolution of desirable kinetics for effective intracellular drug release. These novel approaches therefore could pave the way to the wide and fruitful applications in nanomedicine delivery from laboratories to clinical medicine.

\section{REFERENCES}

[1] Chowdhury, E.H. and Akaike, T. (2005) Advances in fabrication of calcium phosphate nano-composites for Smart Delivery of DNA and RNA to mammalian cells. Current Analytical Chemistry, 2, 187-192. doi:10.2174/1573411054021592

[2] Chowdhury, E.H. and Akaike, T. (2005) Bio-functional inorganic materials: An attractive branch of gene-based 
nano-medicine delivery for $21^{\text {st }}$ century. Current Gene Therapy, 5, 669-676. doi:10.2174/156652305774964613

[3] Chowdhury, E.H., Kutsuzawa, K. and Akaike, T. (2005) Designing Smart nano-apatite Composites: The Emerging era of non-viral gene delivery. Gene Therapy \& Molecular Biology, 9, 301-316.

[4] Chowdhury, E.H. (2007) pH-sensitive nano-crystals of carbonate apatite for smart and cell-specific transgene delivery. Expert Opinion on Drug Delivery, 4, 193-196. doi:10.1517/17425247.4.3.193

[5] Chowdhury, E.H. (2009) Nuclear targeting of viral and non-viral DNA. Expert Opinion on Drug Delivery, 6, 697-703. doi:10.1517/17425240903025744

[6] Chowdhury, E.H. and Akaike, T. (2005) Integrin-targeted gene delivery: A common approach for advanced viral and non-viral vectors. Gene Therapy \& Molecular Biology, 9, 431-444.

[7] Chowdhury, E.H. and Akaike, T. (2007) pH-sensitive inorganic nano-particles and their precise cell targetbility: An efficient gene delivery and expression system. Current Chemical Biology, 1, 201-213.

[8] Chowdhury, E.H. (2008) Self-assembly of DNA and celladhesive proteins onto $\mathrm{pH}$-sensitive inorganic crystals for precise and efficient transgene delivery. Current Pharmaceutical Design, 14, 2212-2228.

doi: $10.2174 / 138161208785740207$

[9] Chowdhury, E.H. (2011) Strategies for tumor-directed delivery of siRNA. Expert Opinion on Drug Delivery, 8, 389-401. doi:10.1517/17425247.2011.554817

[10] Chowdhury, E.H. and Akaike, T. (2005) A Bio-recognition device developed onto nano-crystals of carbonate apatite for cell-targeted gene delivery. Biotechnology and Bioengineering, 90, 414-421. doi:10.1002/bit.20398

[11] Graham, F.L. and van der Eb, A.J. (1973) A new technique for the assay of infectivity of human adenovirus 5 DNA. Virology, 52, 456-467. doi:10.1016/0042-6822(73)90341-3

[12] Batard, P., Jordan, M. and Wurm, F. (2001) Transfer of high copy number plasmid into mammalian cells by calcium phosphate transfection. Gene, 270, 61-68. doi:10.1016/S0378-1119(01)00467-X

[13] Chowdhury, E.H., Kunou, M., Nagaoka, M., Kundu, A.K., Hoshiba, T. and Akaike, T. (2004) High-efficiency gene delivery for expression in mammalian cells by nanoprecipitates of $\mathrm{Ca}-\mathrm{Mg}$ phosphate. Gene, 341, 77-82. doi:10.1016/j.gene.2004.07.015

[14] Okazaki, M., Yoshida, Y., Yamaguchi, S., Kaneno, M. and Elliott J.C. (2001) Affinity binding phenomena of DNA onto apatite crystals. Biomaterials, 22, 2459-2464. doi:10.1016/S0142-9612(00)00433-6

[15] Hasan, M.T., Subbaroyan, R. and Chang, T.Y. (1991) Highefficiency stable gene transfection using chloroquinetreated Chinese hamster ovary cells. Somatic Cell and Molecular Genetics, 17, 513-517. doi:10.1007/BF01233175

[16] Luthman, H. and Magnusson, G. (1983) High efficiency polyoma DNA transfection of chloroquine treated cells. $\mathrm{Nu}$ cleic Acids Research, 11, 1295-1308. doi:10.1093/nar/11.5.1295

[17] Jordan, M., Schallhorn, A. and Wurm, F.M. (1996) Transfecting mammalian cells: Optimization of critical parameters affecting calcium-phosphate precipitate formation. Nucleic Acids Research, 24, 596-601. doi:10.1093/nar/24.4.596

[18] Chowdhury, E.H., Sasagawa, T., Nagaoka, M., Kundu, A. K. and Akaike, T. (2003) Transfecting mammalian cells by DNA/calcium phosphate precipitates: Effect of temperature and $\mathrm{pH}$ on precipitation. Analytical Biochemistry, 314, 316-318. doi:10.1016/S0003-2697(02)00648-6

[19] Chowdhury, E.H., Megumi, K., Harada, I., Kundu, A.K. and Akaike, T. (2004) Dramatic effect of $\mathrm{Mg}(2+)$ on tranfecting mammalian cells by DNA/calcium phosphate precipitates. Analytical Biochemistry, 328, 96-97. doi:10.1016/j.ab.2004.01.009

[20] Chowdhury, E.H., Maruyama, A., Nagaoka, M., Hirose, S., Megumi, K. and Akaike, T. (2006) pH-sensing nanocrystals of carbonate apatite: Effects on intracellular delivery and release of DNA for efficient expression into mammalian cells. Gene, 376, 87-94. doi:10.1016/j.gene.2006.02.028

[21] Chowdhury, E.H. and Akaike, T. (2007) High performance DNA nano-carriers of carbonate apatite: Multiple factors in regulation of particle synthesis and transfection efficiency. International Journal of Nanomedicine, 2, 101-106. doi:10.2147/nano.2007.2.1.101

[22] Chowdhury, E.H., Nagaoka, M., Ogiwara, K., Zohra, F.T., Kutsuzawa, K., Tada, S., Kitamura, C. and Akaike, T. (2005) Integrin-supported fast rate intracellular delivery of plasmid DNA by ECM protein embedded-calcium phosphate complexes. Biochemistry (USA), 44, 12273-12278. doi:10.1021/bi050595g

[23] Chowdhury, E.H. and T. Akaike. (2006) Fibronectin-coated nano-precipitates of calcium-magnesium phosphate for integrin-targeted gene delivery. Journal of Controlled Release, 116, 68-69. doi:10.1016/j.jconrel.2006.09.054

[24] Kutsuzawa, K., Chowdhury, E.H., Nagaoka, M., Maruyama, K., Akiyama, Y. and Akaike T. (2006) Surface functionalization of inorganic nano-crystals with fibronectin and E-cadherin chimera synergistically accelerate transgene delivery into embryonic stem cells. Biochemical and Biophysical Research Communications (BBRC), 350, 514 520. doi:10.1016/j.bbrc.2006.09.081

[25] Kutsuzawa, K., Maruyama, K., Akiyama, T., Akaike, T. and Chowdhury, E.H. (2008) Efficient transfection of mouse embryonic stem cells with cell-adhesive protein-embedded inorganic nano-carrier. Analytical Biochemistry, 372, 122-124. doi:10.1016/j.ab.2007.06.033

[26] Kutsuzawa, K., Akaike, T. and Chowdhury, E.H. (2008) The influence of the cell adhesive proteins E-cadherin and fibronectin embedded in carbonate-apatite DNA carrier on transgene delivery and expression in a mouse embryonic stem cell line. Biomaterials, 29, 370-376. doi:10.1016/j.biomaterials.2007.09.011

[27] Kutsuzawa, K., Maruyama, K., Akiyama, T., Akaike, T. and Chowdhury, E.H. (2007) Protein kinase C activation enhances transfection efficacy of cell-adhesive proteinanchored carbonate apatite nano-crystals. Analytical Bio- 
chemistry, 371, 116-117. doi:10.1016/j.ab.2007.05.029

[28] Kutsuzawa, K., Tada, S., Hossain, S., Fukuda, K., Maruyama, K., Akiyama, Y., Akaike, T. and Chowdhury, E.H. (2009) Disrupting actin filaments promote efficient trans- fection of a leukemia cell line using cell adhesive protein-embedded carbonate apatite particles. Analytical Biochemistry, 388, 164-166. doi:10.1016/j.ab.2009.02.006 